\title{
Escherichia coli virulence influences the roles of sex hormone receptors in female dogs with simulated pyometra
}

\author{
CUNZHONG QIAN and JIAFA HOU \\ Department of Clinical Veterinary Medicine, College of Veterinary Medicine, \\ Nanjing Agriculture University, Nanjing, Jiangsu 210095, P.R. China
}

Received April 27, 2016; Accepted March 31, 2017

DOI: $10.3892 /$ etm.2017.4894

\begin{abstract}
The present study aimed to investigate whether Escherichia coli virulence affects the roles of sex hormone receptors in female dogs with simulated pyometra. A total of 33 healthy, nulliparous, crossbred female dogs were divided into four groups, with $10 \mathrm{dogs}$ in each of the three experimental groups and 3 dogs in the control group. Estradiol was administrated to female dogs in group 1 continuously at $0.6-4.8 \mathrm{mg} / \mathrm{kg}$ twice daily for 12 days (the dose doubled every three days), followed by intramuscular injection of $0.2-1.8 \mathrm{mg} / \mathrm{kg}$ progesterone. The progesterone was administrated with an initial dose of $0.2 \mu \mathrm{g} / \mathrm{kg}$ and increased $0.2 \mathrm{mg} / \mathrm{kg}$ every three days, twice daily until the maximum of $1.8 \mathrm{mg} / \mathrm{kg}$ for 24 days and maintained at $1.8 \mathrm{mg} / \mathrm{kg}$ for 19 days. Progesterone only was administrated at $1.8 \mathrm{mg} / \mathrm{kg}$ in group 2 (twice daily) for 55 continuous days and only estradiol was administered with an initial dose of $0.6 \mu \mathrm{g} / \mathrm{kg}$ (dose doubled every 3 days for 12 days) in group 3 twice daily and maintained at $4.8 \mathrm{mg} / \mathrm{kg}$ for the following 43 days. A strongly virulent $E$. coli strain, nau-b, and a weakly virulent strain, nau-i, were screened. On the 12th day of diestrus, 5 female dogs in each of the experimental groups were inoculated with E. coli nau-i strain, while the other five in each group were inoculated with nau-b strain. Histopathological changes of uterine tissues were microscopically observed 50 days after E. coli inoculation and hormone receptor expression levels were detected by quantitative polymerase chain reaction. Simulated pyometra was observed in dogs administrated with progesterone alone or progesterone combined with estradiol. The clinical symptoms and histopathological observation demonstrated that inoculation with strongly virulent $E$. coli strain, nau-b, caused earlier onset of pyometra symptoms and more severe pyometra
\end{abstract}

Correspondence to: Mr. Jiafa Hou, Department of Clinical Veterinary Medicine, College of Veterinary Medicine, Nanjing Agriculture University, 1 Weigang Road, Xuanwu, Nanjing, Jiangsu 210095, P.R. China

E-mail: jfhou@njau.edu.cn

Key words: canine pyometra model, Escherichia coli virulence, estrogen, progesterone, hormone receptor symptoms compared with the weakly virulent $E$. coli strain, nau-i. Furthermore, estrogen and progesterone receptor levels in dogs with pyometra inoculated with E. coli strain nau-i was higher than those in dogs with pyometra inoculated with $E$. coli strain nau-b. These results indicated that $E$. coli affects the roles of sex hormone receptors in female dogs with simulated pyometra.

\section{Introduction}

Pyometra is a common, metoestral disease in adult, ovary-intact female dogs, which is characterized by endometrial hyperplasia and infiltration of inflammatory cells $(1,2)$, with typical manifestations of lethargy, depression, loss of appetite, vomiting, thirst, polydipsia, polyuria and progressive (tremor) shock (3). The detailed mechanisms underlying its pathogenesis are not fully understood; however, it is believed to be principally attributed to primary hormonal imbalance and secondary bacterial infection (4).

Pyometra predominantly occurs during the metoestrus phase of the estrous cycle, when progesterone is the dominant hormone $(5,6)$. Progesterone may induce endometrial proliferation and uterine glandular secretion, decrease myometrial contraction and induce closure of the cervix (7). Progesterone also inhibits the bactericidal activity of the uterus against Escherichia coli, while estrogen stimulates the clearance of bacteria (8). Estrogen increases the uterine sensitivity and reaction to progesterone (7). The circulating exogenous or endogenous estrogen concentration affects the distribution of estrogen receptors (ERs) within the uterus of female dogs. Notably, ERs and progesterone receptors (PRs) have also been implicated in the pathogenesis of pyometra, as alteration in their expression has been observed in the uterine wall of female dogs with pyometra $(9,10)$, although the changes are not consistent among different studies $(9,10)$.

$E$. coli is the bacterial agent most commonly isolated from the infected uterus in female dogs with pyometra (11), and the strains are clonally related to those isolated from urinary tract infections (12). Furthermore, it has been reported that the epithelium and endometrium of the urinary tract have affinity to $E$. coli when sensitized by a high level of progesterone (13). Previous studies of $E$. coli isolated from canine pyometra have indicated a variable frequency of virulence genes encoding adhesins (including fimH, papC and papGIII), 
toxins (including $h l y \mathrm{~A} / \mathrm{F}$, usp and $a s t A$ ) and other factors (such as those involved in escape from host defenses and iron acquisition) $(11,14,15)$.

The aim of the present study was to investigate whether $E$. coli virulence affects the roles of sex hormone receptors in female dogs with simulated pyometra. The study was designed to provide more information about the roles of $E$. coli and hormone receptors in the etiology of pyometra.

\section{Materials and methods}

Isolation and identification of E. coli strains. About 1-3 ml pus was collected from each uterus (total 26 uteri) that were came from female dogs undergoing surgery to remove the uterus, diagnosed with canine pyometra at Nanjing Agricultural University Animal Hospital (Nanjing, China). The pus sample was first incubated in Lysogeny broth (LB; BioSyntech Inc., Beijing, China) at $37^{\circ} \mathrm{C}$ for $24 \mathrm{~h}$, followed by subsequent incubation in MacConkey medium (BioSyntech Inc.) at $37^{\circ} \mathrm{C}$ for $24 \mathrm{~h}$. A single red smooth colony was stained with Gram's stain and then examined under a light microscope (Olympus CX23; Olympus Corporation, Tokyo, Japan). The red, short, bacilliform bacteria were selected and first inoculated into LB (1:100 dilution) at $37^{\circ} \mathrm{C}$ for $24 \mathrm{~h}$ and then subcultured at a dilution of 1:100 in eosin-methylene blue medium at $37^{\circ} \mathrm{C}$ for $24 \mathrm{~h}$. A single black colony with metallic luster was stained with Gram's stain and then examined under a light microscope. The red, short, bacilliform bacteria were considered to be $E$. coli isolates, which were then inoculated into LB (1:100 dilution) at $37^{\circ} \mathrm{C}$ for $24 \mathrm{~h}$, and subsequently on MacConkey medium (1:100 dilution) at $37^{\circ} \mathrm{C}$ for $24 \mathrm{~h}$.

Biochemical identification of $E$. coli was performed using the national standard methods, as previously described (16). Only isolates meeting the following criteria were considered to be E. coli: i) Positive results in the indole and methyl red tests; ii) negative results in the Voges-Proskauer and citrate tests; and iii) producing acids or alkali, with or without $\mathrm{H}_{2} \mathrm{~S}$ on the slants, while producing acids on the slants without $\mathrm{H}_{2} \mathrm{~S}$ at the bottom in the triple sugar iron agar slant test. Finally, the cultures were stored at $-70^{\circ} \mathrm{C}$ after mixing with $50 \%$ glycerol at $1: 1$.

Detection of virulence genes in E. coli strains. E. coli DNA was isolated using the OMEGA Bacterial Genomic DNA Extraction kit (Omega Bio-Tek, Inc., Norcross, GA, USA), according to the manufacturer's instructions. The extracted DNA was then stored at $-20^{\circ} \mathrm{C}$ for later use. Polymerase chain reaction (PCR) performed on ABI Prism 7300 Detection System (Applied Biosystems Inc., Carlsbad, CA, USA) was used to detect seven major genes causing urinary tract infection in the isolated E. coli strains: hlyA, sfa, fim, pap, papC, pap GIII and $u s p$. Specific primers (Table I) were designed with reference to the conserved sequences described in previous studies $(15,17)$. GAPDH was used as a control gene, and the sequence of GAPDH primer was as follows: Forward 5'-ATG ACTATCAAAGTAGGTATCA-3', reverse 5'-TTATTTGGA GATGTGAGCGATCAG-3'. PCR reactions were performed in a $25 \mu 1$ reaction volume containing $12.5 \mu 1$ PCR MasterMix (Bioteke Corporation, Beijing, China), $1 \mu \mathrm{l}$ upstream and downstream primer each, $8.5 \mu \mathrm{l} \mathrm{ddH}_{2} \mathrm{O}$ and $2 \mu \mathrm{l}$ DNA template. PCR products were identified by $1.0 \%$ agarose gel electrophoresis. The amplification conditions was as follows: 30 cycles of $94^{\circ} \mathrm{C}$ for $1 \mathrm{~min}$, annealing at specific temperatures for each gene (Table I), $72^{\circ} \mathrm{C}$ for 2 mins and $72^{\circ} \mathrm{C}$ for 7 mins. The experiment was repeated three times.

Determination of the half lethal dose $\left(L D_{50}\right)$ of the isolated E. coli strains. A total of 250, 4-week old ICR mice (18-22 g) of 125 male and 125 female, 6-8 weeks old, were obtained from Laboratory Animal Center \& Institute of Comparative Medicine of Yangzhou University (Yangzhou, China). The animals were maintained on a 12-h-dark/12-h-light cycle at $\sim 20^{\circ} \mathrm{C}$ and $50-60 \%$ humidity, with ad libitum access to food and water during the experiments. The ICR mice were randomly divided into 10 groups of 25 animals each, including 9 experimental groups and one control group. The 9 experimental groups were each administered a different strain of E. coli; nau-h, nau-d, nau-o, nau-q, nau-j, nau-b, nau-f, nau-i and nau-w, respectively. Each group was randomly divided into five subgroups of 5 mice each. $E$. coli cell cultures were diluted into five concentrations (Table II) with phosphate-buffered saline. E. coli cell culture $(0.2 \mathrm{ml})$ of different concentrations was intraperitoneally injected into mice in the experimental subgroups, while $0.2 \mathrm{ml}$ of sterile saline was intraperitoneally injected into each control mouse. The clinical performance including pneumorrhagia, renal edema and intestine wall thickness of all mice were observed once every $12 \mathrm{~h}$ for 7 days consecutively. Pathological changes were observed at necropsy and recorded. Liver, spleen, kidney and bladder smears were also observed under a light microscope to examine E. coli morphology. The present study was approved by the Animal Ethics Committee of the Nanjing Police Dog Research Institute of Ministry of Public Security (Nanjing, China). To minimuse suffering, all surviving mice were sacrificed by decapitation, following the induction of anesthesia using 3\% pentobarbital (Sigma-Aldrich; Merck KGaA) at dose of $200 \mathrm{mg} / \mathrm{kg}$ injected via the peritoneal cavity.

Grouping of female dogs and hormone treatment. A total of 33 healthy, nulliparous, crossbred female dogs (age, 2-3 years; weight, 8-12 kg) were purchased from Experimental animal center of Yangzhou University (Yangzhou, China). The experimental female dogs were divided into four groups, with 10 dogs in each of the three experimental groups and three dogs in the control group. Each dog was housed separately in the animal room and maintained in a 12-h light/dark cycle at $\sim 20^{\circ} \mathrm{C}$ and $50-60 \%$ humidity with ad libitum access to commercial dog food and water during the experiments. After 2 weeks, all female dogs were mentally normal assessed with good activity (forceful and active limbs), normal temperature within the range of $38-39^{\circ} \mathrm{C}$, with a normal eating action and good appetite, and a vaginal smear test was performed. The present research was approved by the Animal Ethics Committee of the Nanjing Police Dog Research Institute of Ministry of Public Security (Nanjing, China).

Prior to ovariectomy, general anesthesia was performed using the following anesthetics successively: Subcutaneous injection of $0.04 \mathrm{mg} / \mathrm{kg}$ atropine (Wuhu Kangqi Pharmaceuticals Co., Ltd, Wuhu, China) for pre-anesthesia; $10 \mathrm{~min}$ later, intramuscular injection of $0.05 \mathrm{ml} / \mathrm{kg}$ Sumianxin 
Table I. Primers for the seven virulence genes.

\begin{tabular}{|c|c|c|c|}
\hline Gene & Primer sequence $\left(5^{\prime} \rightarrow 3^{\prime}\right)$ & $\begin{array}{l}\text { Annealing } \\
\text { temperature, }{ }^{\circ} \mathrm{C}\end{array}$ & $\begin{array}{l}\text { Size of amplified } \\
\text { fragments, bp }\end{array}$ \\
\hline hlyA & $\begin{array}{l}\text { F: AACAAGGATAAGCACTGTTCTGGCT } \\
\text { R: ACCATATAAGCGGTCATTCCCGTCA }\end{array}$ & 63 & 1,177 \\
\hline$s f a$ & $\begin{array}{l}\text { F: CGGAGGAGTAATTACAAACCTGGCA } \\
\text { R: CTCCGGAGAACTGGGTGCATCTTAC }\end{array}$ & 63 & 410 \\
\hline fim & $\begin{array}{l}\text { F: GAGAAGAGGTTTGATTTAACTTATTG } \\
\text { R: AGAGCCGCTGTAGAACTGAGG }\end{array}$ & 58 & 559 \\
\hline pap & $\begin{array}{l}\text { F: GCAACAGCAACGCTGGTTGCATCAT } \\
\text { R: AGAGAGAGCCACTCTTATACGGACA }\end{array}$ & 63 & 336 \\
\hline papC & $\begin{array}{l}\text { F: GACGGCTGTACTGCAGGGTGTGGCG } \\
\text { R: ATATCCTTTCTGCAGGGATGCAATA }\end{array}$ & 60 & 328 \\
\hline papGIII & $\begin{array}{l}\text { F: CATGGCTGGTTGTTCCTAAACAT } \\
\text { R: TCCAGAGACTGTGCAGAAGGAC }\end{array}$ & 63 & 421 \\
\hline usp & $\begin{array}{l}\text { F: ATGCTACTGTTTCCGGGTAGTGTGT } \\
\text { R: CATCATGTAGTCGGGGCGTAACAAT }\end{array}$ & 66 & 1,000 \\
\hline
\end{tabular}

F, forward; R, reverse.

Table II. Concentrations of five subgroups for each experimental group.

\begin{tabular}{|c|c|c|}
\hline $\begin{array}{l}\text { Group } \\
\text { number }\end{array}$ & Strain & Concentrations, CFU \\
\hline 1 & nau-h & $\begin{array}{l}7 \times 10^{7} ; 4.67 \times 10^{7} ; 3.10 \times 10^{7} ; \\
2.07 \times 10^{7} ; 1.38 \times 10^{7}\end{array}$ \\
\hline 2 & nau-d & $\begin{array}{l}8 \times 10^{8} ; 5.30 \times 10^{8} ; 3.50 \times 10^{8} \\
2.37 \times 10^{8} ; 1.58 \times 10^{8}\end{array}$ \\
\hline 3 & nau-o & $\begin{array}{l}7 \times 10^{7} ; 3.50 \times 10^{7} ; 1.75 \times 10^{7} \\
8.75 \times 10^{6} ; 4.38 \times 10^{6}\end{array}$ \\
\hline 4 & nau-q & $\begin{array}{l}7 \times 10^{7} ; 3.50 \times 10^{7} ; 1.75 \times 10^{7} ; \\
8.75 \times 10^{6} ; 4.38 \times 10^{6}\end{array}$ \\
\hline 5 & nau-j & $\begin{array}{l}1 \times 10^{8} ; 6.67 \times 10^{8} ; 4.45 \times 10^{8} \\
2.96 \times 10^{8} ; 1.98 \times 10^{8}\end{array}$ \\
\hline 6 & nau-b & $\begin{array}{l}2.67 \times 10^{7} ; 1.78 \times 10^{7} ; 1.19 \times 10^{7} \\
7.90 \times 10^{6} ; 5.30 \times 10^{6}\end{array}$ \\
\hline 7 & nau-f & $\begin{array}{l}2 \times 10^{8} ; 1 \times 10^{8} ; 5 \times 10^{7} ; 2.50 \times 10^{7} \\
1.25 \times 10^{7}\end{array}$ \\
\hline 8 & nau-i & $\begin{array}{l}1 \times 10^{9} ; 5 \times 10^{8} ; 2.50 \times 10^{8} \\
1.25 \times 10^{8} ; 6.75 \times 10^{7}\end{array}$ \\
\hline 9 & nau-w & $\begin{array}{l}1 \times 10^{8} ; 5 \times 10^{8} ; 2.50 \times 10^{8} \\
1.25 \times 10^{8} ; 6.25 \times 10^{8}\end{array}$ \\
\hline
\end{tabular}

CFU, colony-forming unit.

(Huamu Animal Health Products Co., Ltd., Changchun, China) as basal anesthesia, followed by intravenous injection of $4 \mathrm{mg} / \mathrm{kg}$ Zoletil (Virbac Laboratories, Carros, France) and isoflurane (Hebei Yipin Pharmaceutical Co., Ltd, Hebei, China) at the minimal alveolar concentration of $1.0 \%$. Both ovaries of each dog were removed by a conventional laparotomy along the linea alba. Analgesic (Meloxicam, Qingdao Orbiepharm Co., Ltd, Qingdao, China) was administered once daily continuously for 5 days following the ovariectomy at an initial dosage of $0.2 \mathrm{mg} / \mathrm{kg}$ and subsequent dose of $0.1 \mathrm{mg} / \mathrm{kg}$. After 10 days, the stitches were removed.

After the female dogs had recovered from ovariectomy, estradiol and/or progesterone (Ningbo A second hormone factory, Ningbo, China) were administered 4 weeks later. Briefly, estradiol was administrated to dogs in group 1 by intramuscular injection twice daily for 12 days (dose doubled every 3 days), with an initial dose of $0.6 \mu \mathrm{g} / \mathrm{kg}$, followed by intramuscular injection of progesterone at $0.2-1.8 \mathrm{mg} / \mathrm{kg}$, twice daily for 43 days. The progesterone was administered at an initial dose of $0.2 \mathrm{mg} / \mathrm{kg}$ and was increased by $0.2 \mathrm{mg} / \mathrm{kg}$ every three days, twice daily until the maximum of $1.8 \mathrm{mg} / \mathrm{kg}$ was reached after 24 days, and $1.8 \mathrm{mg} / \mathrm{kg}$ was maintained for a further 19 days. For dogs in group 2, only progesterone was administrated by intramuscular injection at $1.8 \mathrm{mg} / \mathrm{kg}$, twice daily for 55 continuous days. For dogs in group 3, only estradiol was administered by intramuscular injection with an initial dose of $0.6 \mathrm{mg} / \mathrm{kg}$ (dose doubled every 3 days for 12 days) and maintained at $4.8 \mathrm{mg} / \mathrm{kg}$, administered twice daily for the following 43 days.

Determination of estrous cycle. The estrous cycle of female dogs was determined by observation of clinical symptoms, examination of changes in vaginal epithelial cells, routine blood tests and measurement of serum sex hormone levels.

Changes in the vaginal epithelial cells were examined by vaginal smear tests once every 1-2 days after hormone administration began until the proestrus of the simulated estrous cycle was observed, once a day during the estrus and dioestrus stages, and once every 3 days during the anestrus stage until the onset of disease. The keratinization extent of vaginal epithelial cells was evaluated by calculating superficial cell index (SCI), which was defined as the percentage of 
superficial epithelial cells (including anuclear epithelial cells, epithelial cells and large interstitial cells) in total superficial cells and submerged epithelial cells (small interstitial cells and subsidiary basal cells). The first time when SCI was $>80 \%$ was defined as the onset of estrus; an SCI value $>80 \%$ with a small number of neutrophilic cells (NCs) was defined as staying in the estrus stage; a sharp decrease in SCI and a sudden appearance of a great many NCs occupied $70-80 \%$ of total cells in a microscopic field, which was defined as the onset of metestrus. Dogs were considered to be in the diestrus stage when SCI was $<20 \%$ and NLs disappeared.

Meanwhile, blood samples were also collected every 5-7 days after the initiation of hormone administration until the experiments ended, each time at $2 \mathrm{~h}$ after hormone injection. A routine blood test was performed and serum estrogen and progesterone levels were measured. Canine abdominal B-scan ultrasound performed on a MyLab ${ }^{\mathrm{TM}} 30$ VET (Esaote S.p.a., Trezzano S.N., Italy) was used to observe changes in size and shape of uterine horns until the experiments ended.

Inoculation with E. coli. According to the results of vaginal smear and blood sex hormone tests, when the dogs in group 1 were in the 12th day of dioestrus, inoculation with E. coli was performed in all three experimental groups. Before inoculation with $E$. coli into uterus, the enterocoelia of dogs were opened under general anesthesia, as follows: Subcutaneous injection of $0.04 \mathrm{mg} / \mathrm{kg}$ atropine (Wuhu Kangqi Pharmaceuticals Co., Ltd.) for pre-anesthesia; $10 \mathrm{~min}$ later, intramuscular injection of $0.05 \mathrm{ml} / \mathrm{kg}$ Sumianxin (Huamu Animal Health Products Co., Ltd.) as basal anesthesia, followed by intravenous injection of $4 \mathrm{mg} / \mathrm{kg}$ Zoletil (Virbac Laboratories) and isoflurane (Hebei Yipin Pharmaceutical Co., Ltd.) at the minimal alveolar concentration of $1.0 \%$. After anesthesia, a venous indwelling needle was used to pierce the uterine wall of the right uterine horn, followed by injection of $E$. coli cultures at $2 \times 10^{7}$ colony-forming units through a medical injector in the first three groups. After inoculation, the enterocoelia was closed via straticulate saturation of the abdominal wall muscles, subcutaneous tissue and skin, respectively. In each of the experimental groups, five dogs were injected with the strongly virulent $E$. coli strain, nau-b, and the other five dogs were injected with a weakly virulent strain, nau-i. Dogs in the control group were not inoculated with $E$. coli. After injection with different $E$. coli strains, the dogs were assessed for the successful induction of canine pyometra using the following criteria: When there was purulent eduction from vagina, it was diagnosed as the open-cervix pyometra. If numerous white blood cells and pus cells were detected by vaginal smear, in addition to the uterus augmentation to some extent were also detected, it was diagnosed as the closed-cervix pyometra.

Histopathological observation of uterine tissues. All dogs were euthanized using 3\% sodium pentobarbital $(90 \mathrm{mg} / \mathrm{kg}$, Beijing Propbs Biotechnology Co., Ltd.) by intravenous injection, 80 days after E. coli inoculation. Afterwards, the uterus and the vaginal tissues were removed by laparotomy. A middle section of uterine horn was collected from each side and fixed in $10 \%$ neutral formaldehyde at $4^{\circ} \mathrm{C}$ for $24 \mathrm{~h}$, followed by preparation into $5 \mu \mathrm{m}$ paraffin-embedded sections, which were subjected to dewaxing in xylene I and II, each for $10 \mathrm{~min}$.
Subsequently, sections were stained with hematoxylin for $5 \mathrm{~min}$ at room temperature, stained with $0.5 \%$ eosin for $2 \mathrm{~min}$, and treated with xylene twice, 5 min each time, and mounted.

Histopathological changes in uterine mucosa, stroma, glands and myometrium were observed under a microscope at x100 and x400 magnification. Endometrial thickness, myometrium thickness and uterine wall thickness were measured, and the ratio of endometrial thickness to myometrium thickness was calculated. The percentage of vesicle area in the total endometrium area was also calculated.

Determination of $E R$ and $P R$ expression levels by reverse transcription-quantitative $P C R$ (RT-qPCR). RNA was extracted from the cultured uterus tissue cells using a RNAiso Plus kit (Takara Bio, Inc., Dalian, China) following the manufacturer's instructions. RNase-free Dnase I (Takara Bio., Inc.) was used to remove any genomic DNA contamination. RT was performed on ABI Prism 7300 Detection System (Applied Biosystems Inc. Carlsbad, CA, USA) in a $20 \mu \mathrm{l}$ reaction system using the PrimeScript RT Master Mix kit (Takara Bio, Inc.), which contained $\sim 2 \mu \mathrm{g}$ RNA template, $4 \mu$ l buffer $(5 \mathrm{X})$, $2 \mu \mathrm{ldNTP}(10 \mathrm{mM}), 1 \mu \mathrm{l}$ oligo (dT) $18(10 \mu \mathrm{M}), 1 \mu \mathrm{l}$ RNase inhibitor, $1 \mu \mathrm{l}$ Rever-Tra Ace- $\alpha$ reverse transcriptase and $9 \mu \mathrm{l}$ RNase free $\mathrm{dH}_{2} \mathrm{O}$. Subsequently, a $25 \mu \mathrm{l}$ PCR reaction system was used for DNA amplification, and the system contained $12.5 \mu 1$ 2xSYBR Green I master Mix (Takara Bio., Inc.) in addition to $1 \mu \mathrm{l}$ upstream and downstream primer each, $10 \mu \mathrm{l}$

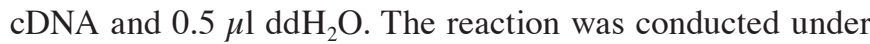
the following conditions: Denaturation at $94^{\circ} \mathrm{C}$ for $4 \mathrm{~min}$, followed by 20-32 cycles of denaturation at $94^{\circ} \mathrm{C}$ for $40 \mathrm{sec}$, annealing at $55^{\circ} \mathrm{C}$ for $40 \mathrm{sec}$, extension at $72^{\circ} \mathrm{C}$ for $40 \mathrm{sec}$ and a final extension at $72^{\circ} \mathrm{C}$ for $7 \mathrm{~min}$. The PCR products were examined by $1 \%$ agarose gel electrophoresis. The primers were as follows: GAPDH (as a control), forward 5'-AAAGCTGCC AAATATGACGA-3' and reverse 5'-TTTCGACGGTTTATA CTGCT-3'; ER, forward 5'-GACCCATCCAGACCCTTCA-3' and reverse 5'-CTGGGTAGGTCTGGGAAGT-3'; and PR, forward 5'-TAGCTCACAGCGTTTCTACCA-3' and reverse 5'-ATCGAGTGTCGCAAAGATGGT-3'. mRNA expression levels were quantified using the $2^{-\Delta \Delta C q}$ method (18), and the experiment was repeated three times.

Statistical analysis. All data were presented as the mean \pm standard error of the mean. Duncan's multiple analysis was performed by using SPSS, version 20.0 (IBM Corp., Armonk, NY, USA). GraphPad Prism version 5.0 software (GraphPad Software, Inc., La Jolla, CA, USA) was used for multiple comparisons by ordinary one-way analysis of variance analyses followed by least-significant difference test as the post-hoc analysis. $\mathrm{P}<0.05$ was considered to indicate a statistically significant difference.

\section{Results}

Screening of E. coli strains. Expression of 9 virulence genes ( hlyA, sfa, fim, pap, papC, icuD, cnfl, papGIII and usp) among the 11 isolated E. coli strains was evaluated by PCR. Gene hlyA encoding hemolysin, sfa encoding S fimbriae, pap encoding $\mathrm{P}$ fimbriae, papC encoding P fimbriae and papGIII encoding adhesin were all expressed in $63.6 \%$ of the strains. The fim 
Table III. Determination of $\mathrm{LD}_{50}$ values in mice.

\begin{tabular}{lccc}
\hline Strain & $\begin{array}{c}\text { Number of } \\
\text { bacteria, } \\
\text { CFU }\end{array}$ & $\begin{array}{c}\text { Mortality/ } \\
\text { subgroup } \\
(\mathrm{n}=5 \text { per group })\end{array}$ & $\mathrm{LD}_{50}, \mathrm{CFU}$ \\
\hline nau-b & $2.67 \times 10^{7}-5.3 \times 10^{6}$ & $5,4,3,2,0$ & $1.0520 \times 10^{7}$ \\
nau-i & $1 \times 10^{9}-6.25 \times 10^{7}$ & $5,4,3,2,0$ & $2.0421 \times 10^{8}$ \\
nau-h & $7 \times 10^{7}-1.38 \times 10^{7}$ & $5,5,3,2,0$ & $2.5384 \times 10^{7}$ \\
nau-d & $8 \times 10^{8}-1.58 \times 10^{8}$ & $5,4,2,0,0$ & $4.0365 \times 10^{8}$ \\
nau-o & $7 \times 10^{7}-4.375 \times 10^{6}$ & $5,3,1,0,0$ & $2.8188 \times 10^{7}$ \\
nau-q & $7 \times 10^{7}-4.375 \times 10^{6}$ & $5,4,3,0,0$ & $1.9186 \times 10^{7}$ \\
nau-j & $6.67 \times 10^{8}-1 \times 10^{8}$ & $5,5,4,2,0$ & $3.3629 \times 10^{8}$ \\
nau-f & $2 \times 10^{8}-1.25 \times 10^{7}$ & $5,3,1,0,0$ & $8.0536 \times 10^{7}$ \\
nau-w & $6.25 \times 10^{8}-1 \times 10^{8}$ & $5,5,3,1,0$ & $2.0125 \times 10^{7}$ \\
Control & 0 & $0,0,0,0,0$ & - \\
\hline
\end{tabular}

$\mathrm{LD}_{50}$, median lethal dose; $\mathrm{CFU}$, colony-forming unit.

Table IV. Expression of virulence genes in Escherichia coli strains, nau-b and nau-i.

Escherichia coli strain

\begin{tabular}{lcc}
\cline { 2 - 3 } Virulence gene & nau-b & nau-i \\
\hline sfa & + & - \\
hlyA & + & - \\
fim & + & + \\
pap & + & - \\
icuD & - & - \\
cnfl & - & - \\
papC & + & - \\
papGIII & + & - \\
usp & + & - \\
\hline
\end{tabular}

gene encoding type I fimbriae was expressed in $90.9 \%$ of the strains and usp encoding a uropathogenic-specific protein was expressed in $54.5 \%$ of the strains.

Listlessness, loss of appetite and huddling in groups were observed in each test mouse $24 \mathrm{~h}$ after intraperitoneal injection of E. coli cultures. Mortality occurred in 114 mice within 24-72 $\mathrm{h}$ following inoculation (Table III) and mice that survived longer than $72 \mathrm{~h}$ were decapitated. Serous exudate was found at autopsy in the enterocoelia of all mice. Kidney swelling and uterine edema were observed in 96 mice. Gram-negative short, bacilliform bacteria were observed on the smears of liver, spleen, kidney and bladder of all mice that succumbed. No abnormalities were observed in the control mice.

Taking $\mathrm{LD}_{50}$ values and the expression of virulence genes into consideration (Tables III and IV), a strongly virulent E. coli strain containing seven virulence genes ( $h l y A$, sfa, fim, pap, papC, pap GIII and $u s p)$, named nau-b (LD50; $\left.2.0421 \times 10^{8}\right)$, and a weakly virulent strain containing fim only, named nau-I
(LD50; $1.0520 \times 10^{7)}$, were selected for later inoculation in female dogs.

Identification of estrous cycle and pyometra in female dogs. The blood estrogen and progesterone levels changed with exogenous hormone levels in female dogs. According to the vaginal smear test and blood sex hormone test, a complete, simulated estrous cycle, including proestrus, estrus, metestrus, dioestrus and anestrus, was observed in the female dogs administrated with both estradiol and progesterone. According to the status of the cervix, pyometra symptoms were observed at the end of dioestrus. In female dogs administered progesterone alone in group 2, were identified to remain in the dioestrus and were not observed to move into other estrous cycles, thus dioestrus was longer than for other groups, and pyometra symptoms were also observed at the end of the study. The onset time of pyometra in dogs in groups 1 and 2 inoculated with $E$. coli strain nau-b was on day $71 \pm 2.5$, and that for the dogs inoculated with $E$. coli strain nau-i was on day $74 \pm 3.5$. Except for one dog with closed-cervix pyometra in each group, the other dogs in groups 1 and 2 had open-cervix pyometra, with symptoms of purulent secretion from vagina and varying degrees of uterine enlargement according to the B-scan ultrasound. Swelling and congestion of uterine horns was demonstrated at autopsy in group 1 and 2 female dogs, with uterine horn diameter of 2-3.8 cm. Varying amounts of reddish-brown liquid with a strong odor were observed in the uterine cavity. Female dogs administrated with estradiol alone were found in the proestrus stage until the end of experiments, and pyometra was not observed until autopsy. Pyometra was not observed in the control group.

The number of red blood cells and hemoglobin concentration were within the normal range in each group throughout the experiment, as were the levels of alanine aminotransferase, alkaline phosphatase, blood urea nitrogen, creatinine and transglutaminase. After E. coli inoculation, there was one dog found with a body temperature range of $39.3-39.6^{\circ} \mathrm{C}$ in each of groups 1 and 2, also with decreased appetite; however, neither dog stopped feeding completely.

Histopathological comparison of uterine horn among female dogs subjected to different treatments. Abundant endometrial glands were observed in the uterine horn of female dogs inoculated with $E$. coli strain nau-b in group 1, as well as complete cystic endometrial hyperplasia (CEH) of the mucous membrane and superficial functional layer. The epithelium of some glands demonstrated papillary hyperplasia, forming labyrinth-like structures (Fig. 1A; magnification, x100). At magnification $\mathrm{x} 400$, the glandular epithelial cells were cylindrical and mucinous, containing abundant, bright cytoplasm, with nuclei located centrally. Mesenchyme was infiltrated by large numbers of inflammatory cells (Fig. 1B). Similar symptoms were observed in the uterine horns of group 1 dogs inoculated with stain nau-i, although $\mathrm{CEH}$ and infiltration of inflammatory cells was less severe.

At low magnification (x100), endometrial mucosa forming plica was observed in the uterine horn of female dogs inoculated with $E$. coli strain nau-b in group 2, with few cylindrical glands on the plica, and infiltration of focal 

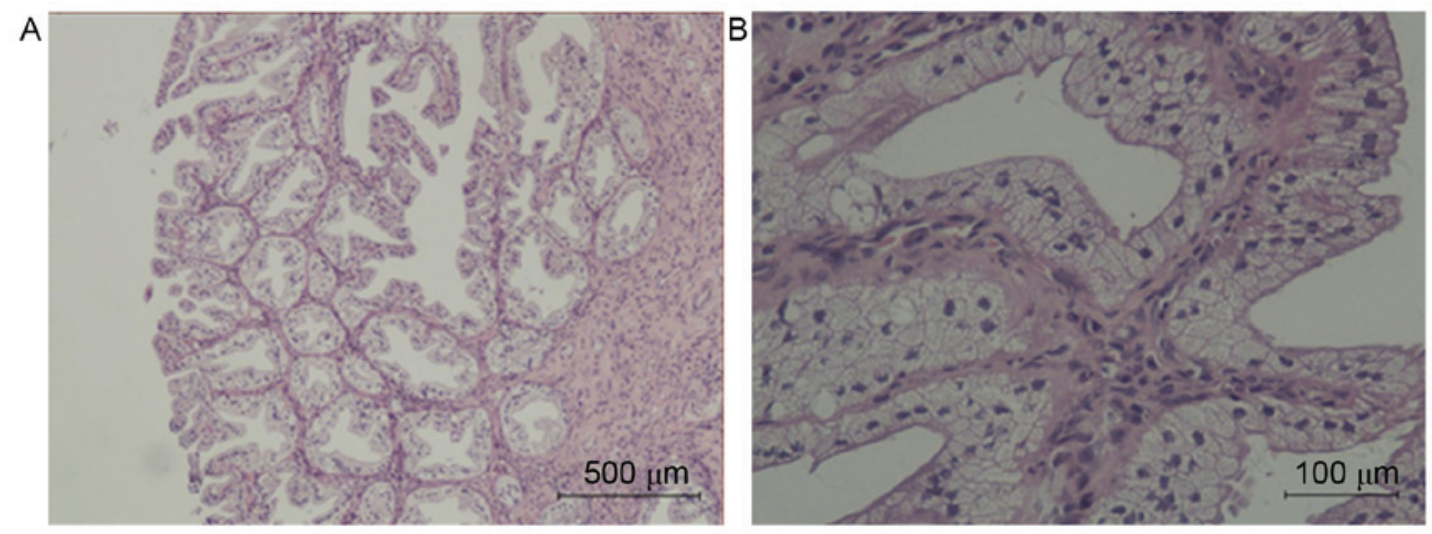

Figure 1. Histopathological observation of uterine tissues stained with hematoxylin and eosin in dogs treated with estradiol and progesterone. (A) Magnification, x100. Scale bar, $500 \mu \mathrm{m}$. (B) Magnification, x400. Scale bar, $100 \mu \mathrm{m}$.
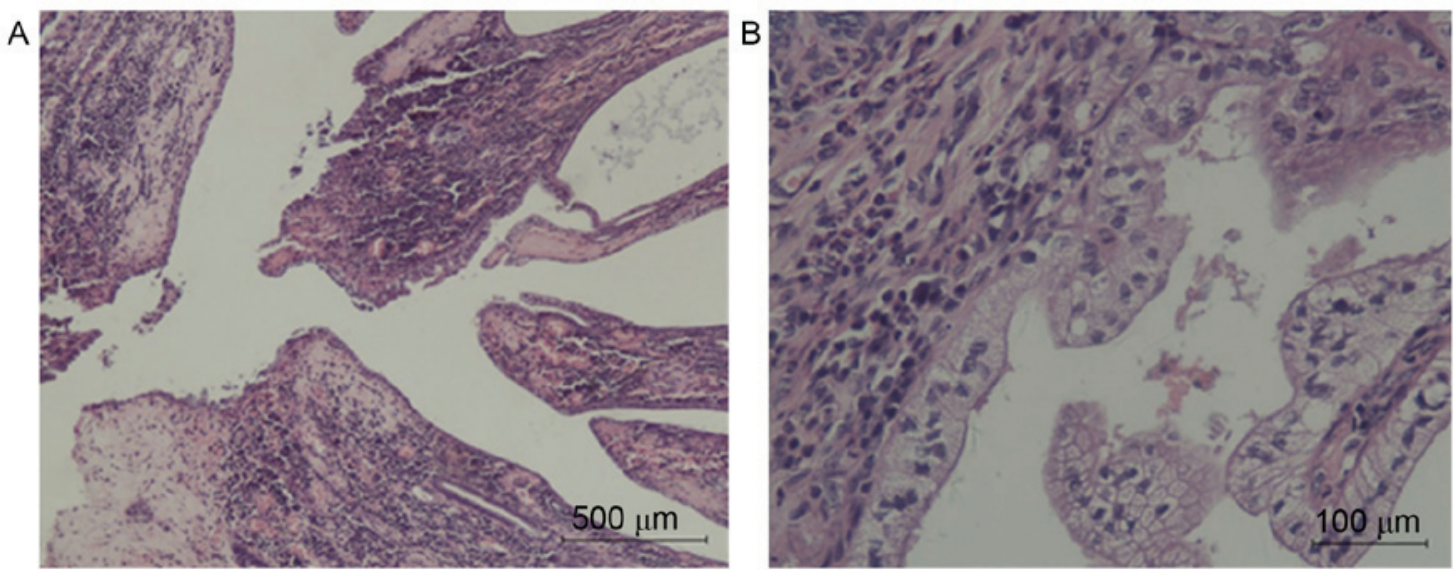

Figure 2. Histopathological observation of uterine tissues stained with hematoxylin and eosin in dogs treated with progesterone. (A) Magnification, x100. Scale bar, $500 \mu \mathrm{m}$. (B) Magnification, x400. Scale bar, $100 \mu \mathrm{m}$.

A

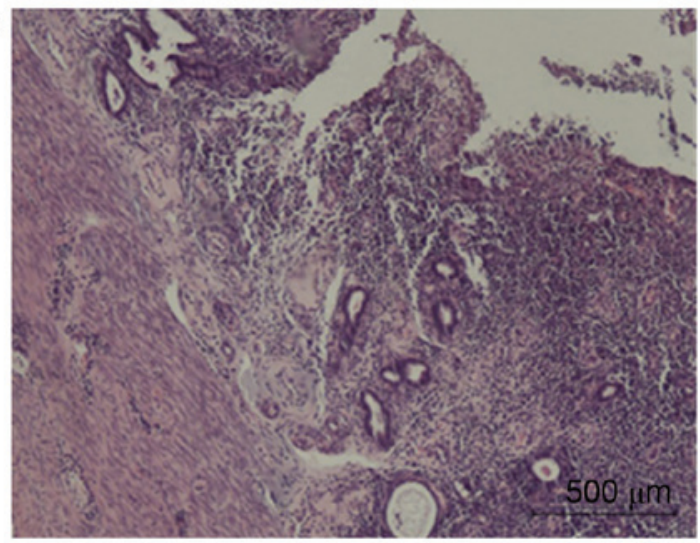

B

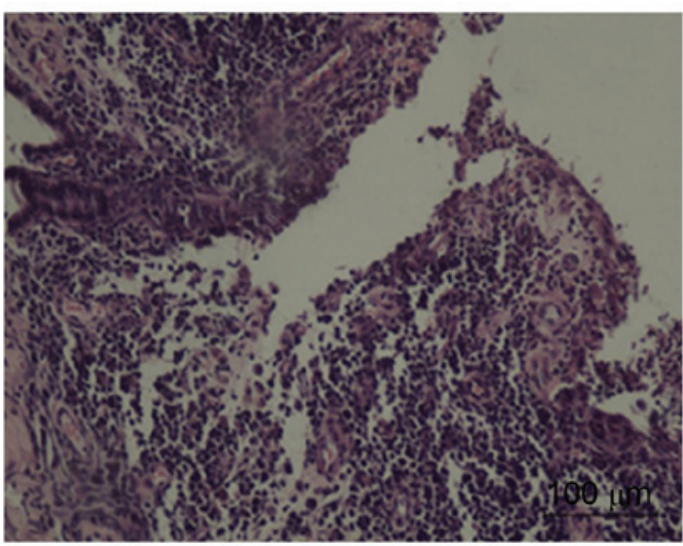

Figure 3. Histopathological observation of uterine tissues stained with hematoxylin and eosin in dogs treated with estradiol. (A) Magnification, x100. Scale bar, $500 \mu \mathrm{m}$. (B) Magnification, $\mathrm{x} 400$. Scale bar, $100 \mu \mathrm{m}$.

inflammatory cells (Fig. 2A). At magnification x400, the endometrial epithelial plica had few glands, and CEH was observed, as well as infiltration by large numbers of plasma cells (Fig. 2B). Female dogs inoculated with nau-i in group 2 displayed similar symptoms at the uterine horns; however, with a less severe degree of CEH and infiltration of inflammatory cells.
The uterine horns of female dogs inoculated with E. coli strain nau-b in group 3 demonstrated fewer endometrial glands and exhibited no secretion by tubular glands or surface erosion; meanwhile myometrium was infiltrated by focal inflammatory cells (Fig. 3A; magnification, x100). The lumina of endometrial glands were observed to be small and the mesenchyme was infiltrated by inflammatory cells (Fig. 3B, 
magnification, $x 400)$. Female dogs inoculated with nau-i in group 3 demonstrated similar symptoms at the uterine horns as those inoculated with nau-b.

In the uterine horn of female dogs in the control group at low magnification (x100), the surface of the uterine cavity had a single layer of columnar epithelium and exhibited proliferation of subepithelial fibrous tissue; no glands were observed; a thick mesenchyme was observed, and there was no obvious infiltration of inflammatory cells (Fig. 4A). A single layer of columnar epithelium contained a small number of stromal cells, no glands, infiltration by a small amount of lymphocytes and plasma cells, and a small amount of secretion in the uterine cavity (Fig. 4B; magnification, x400).

Comparison of biometric indices among female dogs subjected to different treatments. Endometrial thickness, myometrium thickness, uterine wall thickness and vacuole area were the largest in group 2 (with the exception of $E$. coli nau-i endometrial thickness; Table V), indicating that group 2, administrated with only progesterone was significantly more effective at promoting hyperplasia of the uterine wall than groups administrated with estradiol and progesterone in group 1 and only estradiol in group $3(\mathrm{P}<0.05)$. Furthermore, endometrial thickness, myometrium thickness and the thickness of the uterine wall in female dogs inoculated with E. coli nau-b were significantly increased compared with nau-i or the control group $(\mathrm{P}<0.05$; Table $\mathrm{V})$, indicating that $E$. coli nau-b induced significant hyperplasia of the uterine wall.

Comparison of ER and PR expression levels in uterine horns. ER expression levels in dogs inoculated with nau-i was the highest in group 2, followed by groups 1 and 3, respectively. In dogs inoculated with nau-b, the highest ER expression was exhibited in group 3, and this was significantly increased compared with the control $(\mathrm{P}<0.01$; Fig. 5A). Furthermore, ER expression levels in dogs inoculated with E. coli nau-i in groups 1 and 2 were significantly higher compared with their counterparts in female dogs inoculated with nau-b $(\mathrm{P}<0.01$ and $\mathrm{P}<0.05$, respectively). In group 3 , the ER expression level in dogs inoculated with $E$. coli nau-b was significantly higher than that in dogs inoculated with nau-i ( $\mathrm{P}<0.05$; Fig. 5A).

PR expression level in dogs inoculated with nau-i was the highest in group 1, followed by groups 2 and 3, respectively, with significant differences between the groups $(\mathrm{P}<0.01$; Fig. 5B). PR expression level in dogs inoculated with nau-b was the highest in group 3, followed by groups 1 and 2, respectively. PR expression in dogs inoculated with nau-i was significantly higher in group 2 than group 3 ( $\mathrm{P}<0.05$; Fig. 5B). Furthermore, PR expression levels in dogs inoculated with E. coli nau-i in groups 1 and 2 were also significantly higher than those in their counterparts inoculated with nau-b $(\mathrm{P}<0.01$; Fig. 5B). In group 3, the PR expression level in dogs inoculated with E. coli nau-b was significantly higher than that in dogs inoculated with nau-i ( $\mathrm{P}<0.05$; Fig. 5B).

\section{Discussion}

In the present study, pyometra was only found in female dogs administrated with progesterone alone or progesterone combined with estrogen, irrespective of the virulence of

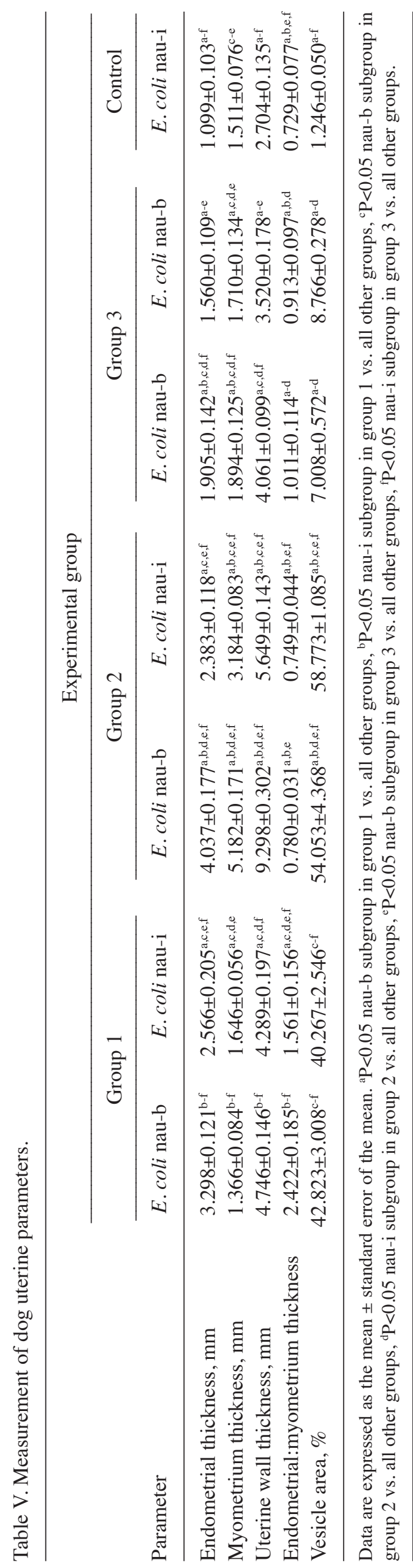



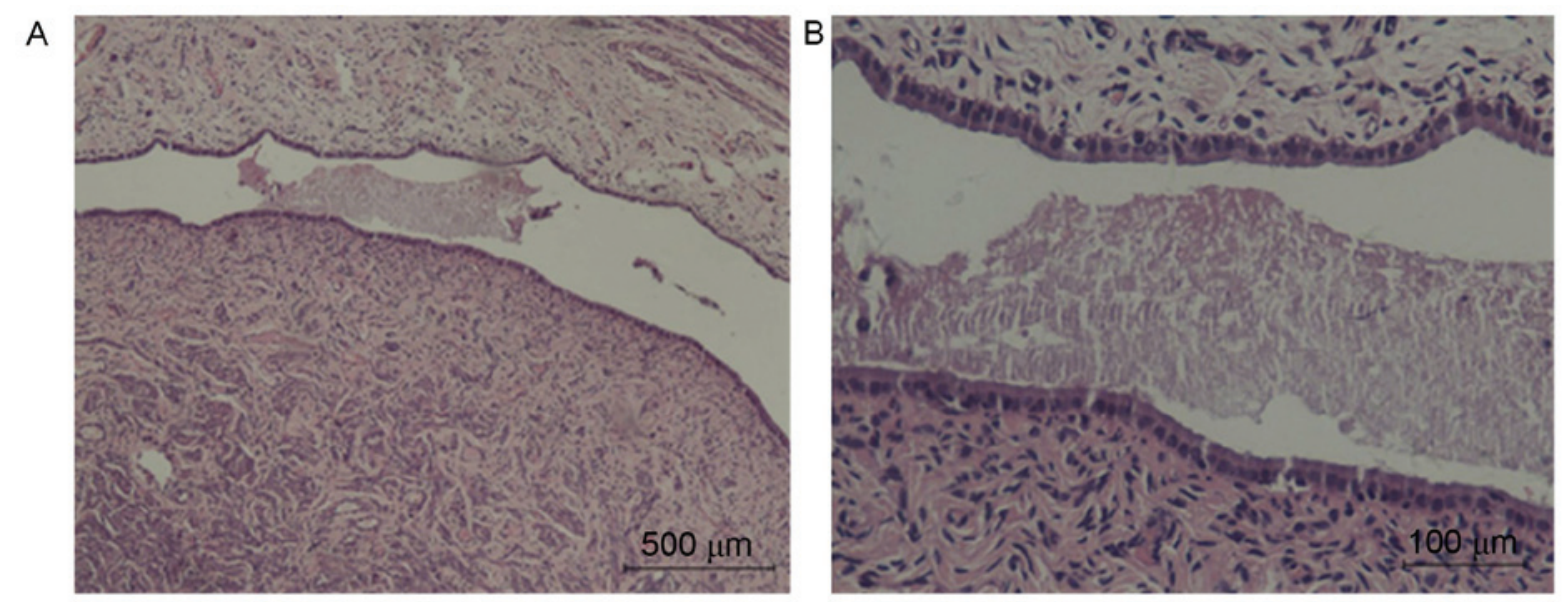

Figure 4. Histopathological observation of uterine tissues stained with hematoxylin and eosin in control dogs. (A) Magnification, x100. Scale bar, $500 \mu \mathrm{m}$. (B) Magnification, $\mathrm{x} 400$. Scale bar, $100 \mu \mathrm{m}$.
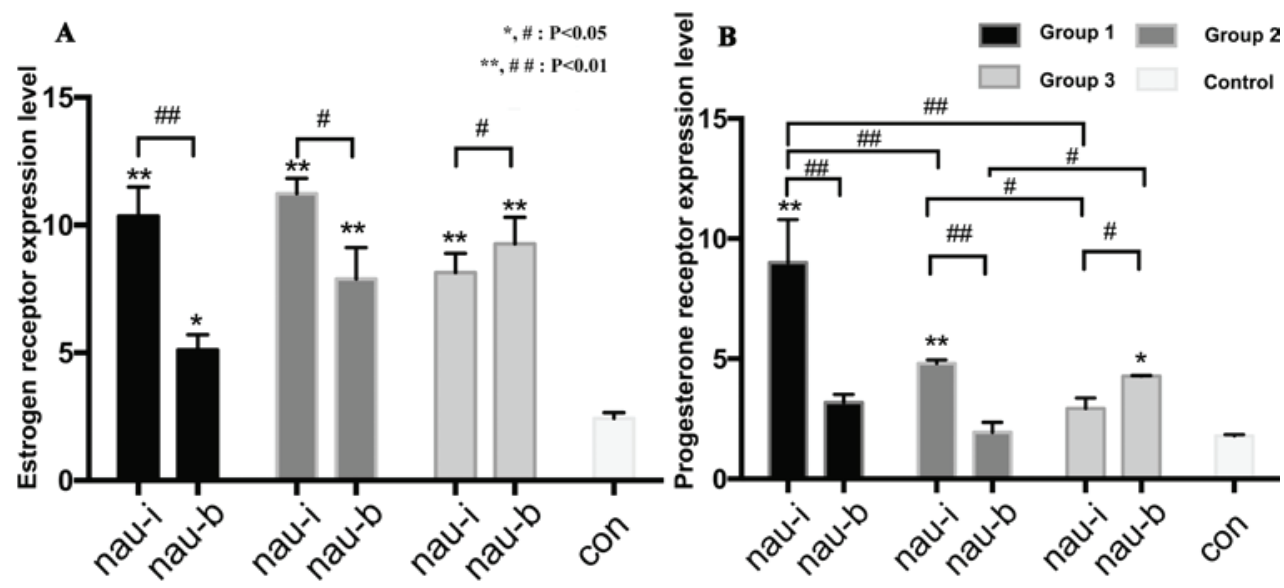

Figure 5. Ratio of estrogen and progesterone receptor expression levels in uterine horns of dogs in each group. (A) Estrogen receptor expression level. (B) Progesterone receptor expression level. Data are expressed as the mean \pm standard error of the mean. nau-i, weakly virulent Escherichia coli strain; nau-b, strongly virulent Escherichia coli strain. ${ }^{*} \mathrm{P}<0.05,{ }^{* *} \mathrm{P}<0.01$ vs. control, ${ }^{,} \mathrm{P}<0.05,{ }^{\# \#} \mathrm{P}<0.05$ vs. corresponding group.

E. coli. This suggested that the occurrence of pyometra was closely related to the status of uteri in female dogs and progesterone had a more critical role in pyometra occurrence as compared with estrogen. This is consistent with previous studies $(19,20)$. A study by Nomura et al (21) demonstrated that the success rate of inducing pyometra was highest when inoculating E. coli at the diestrus stage. Furthermore, plasma progesterone level is highest in the diestrus stage of the estrous cycle (22). Thus, inoculation of E. coli was performed on the 12th day of the diestrus stage of the simulated estrous cycle in the present study, when the progesterone was considered to be at a higher level.

Notably, clinical symptoms, histopathological observation and biometric data revealed more severe pyometra symptoms in female dogs administrated with progesterone and estrogen as compared with those administrated with progesterone alone, when the dogs were inoculated with the same E. coli strain. This may be attributed to the fact that estrogen enhances the stimulatory effects of progesterone on the uterus in female dogs administered with progesterone and estrogen (23). Furthermore, female dogs administered with both progesterone and estradiol demonstrated a higher PR level but lower
ER level compared with those administered with progesterone only when they were inoculated with the same E. coli strain. Thus, a higher PR level may lead to more severe symptoms in dogs with pyometra, whereas the opposite is the case for the ER level. This may be because progesterone causes more severe symptoms via binding to a larger number of receptors in dogs with pyometra.

In the present study, a strongly virulent $E$. coli strain, nau-b, containing seven virulence genes (hlyA, sfa, fim, pap, papC, papGIII and usp), and a weakly virulent strain, nau-I, containing fim only, were used for inoculation in female dogs. The clinical symptoms and histopathological observation indicated that strongly virulent $E$. coli strain, nau-b, caused earlier onset of pyometra symptoms and more severe pyometra symptoms than the weakly virulent $E$. coli strain, nau-i. This suggested that higher bacterial virulence may lead to more severe symptoms. This agrees with previous findings on the pathogenicity of E. coli $(11,14,15,17)$, which was determined by its virulence genes encoding fimbriae, toxins and other factors. Furthermore, ER and PR levels in dogs inoculated with $E$. coli strain nau-i were higher than those inoculated with $E$. coli strain nau-b, indicating that strong bacterial 
virulence is associated with lower receptor level. It is possible that strong bacterial virulence may inhibit the expression of hormone receptors; however, this has not been supported by any previous findings. Currently, views towards the changes in hormone receptor expression among different studies are controversial $(9,10)$. In addition, the association between hormone receptor levels and the severity of pyometra has not been reported. Thus, it is difficult to determine the mechanism underlying lower expression of hormone receptor levels in female dogs inoculated with strongly virulent $E$. coli strains.

The results of the present study suggested that the occurrence of pyometra was closely related to the status of uteri in female dogs and progesterone had a more critical role in pyometra occurrence compared with estrogen. It was demonstrated that a higher PR level may lead to more severe symptoms in female dogs with pyometra, when the female dogs were inoculated with the same E. coli strain. It was also demonstrated that strongly-virulent $E$. coli may induce more severe pyometra symptoms than weakly-virulent $E$. coli, although PR and ER levels were lower in female dogs inoculated with strongly-virulent severity $E$. coli. In conclusion, the present study indicated that $E$. coli may affect the role of sex hormone receptors in pyometra. As there are few relevant studies currently available, the findings of the present study should be further validated.

\section{References}

1. Hardy RM and Osborne CA: Canine pyometra: Pathophysiology, diagnosis, and treatment of uterine and extra-uterine lesions. J Am Anim Hosp Assoc 10: 245-268, 1974.

2. Kempisty B, Bukowska D, Wozna M, Piotrowska $\mathrm{H}$ Jackowska M, Zuraw A, Ciesiolka S, Antosik P, Maryniak H and Ociepa E: Endometritis and pyometra in bitches: A review. Vet Med Czech 58: 289-297, 2013.

3. Barton C: Diseases of the Uterus-Cystic Endometrial Hyperplasia/Pyometra Complex. Handbook of Small Animal Practice. 2nd edition. Churchill Livingstone, NY, pp655-658, 1992.

4. Noakes DE, Dhaliwal GK and England GC: Cystic endometrial hyperplasia/pyometra in dogs: A review of the causes and pathogenesis. J Reprod Fertil Suppl 57: 395-406, 2000.

5. Boryczko Z, Katkiewicz M, Bostedt H and Gajewski Z: Ethiopathogenesis, symptoms, diagnosis, and therapy of pyometra in a bitch. Med Weter 57: 246-250, 2001.

6. Birger M, Dejneka G, Nizanski W and Samborski Z: Selected aspects of diagnostics and therapy of endometritis-pyometritis syndrome in female dogs. Med Weter 54: 301-304, 1998.

7. Smith FO: Canine pyometra. Theriogenology 66: 610-612, 2006.
8. Hawk H, Turner G and Sykes J: The effect of ovarian hormones on the uterine defense mechanism during the early stages of induced infection. Am J Vet Res 21: 644-648, 1960.

9. De Cock H, Vermeirsch H, Ducatelle R and De Schepper J: Immunohistochemical analysis of estrogen receptors in cystic-endometritis-pyometra complex in the bitch. Theriogenology 48: 1035-1047, 1997.

10. Dhaliwal GK, England GC and Noakes DE: Oestrogen and progesterone receptors in the uterine wall of bitches with cystic endometrial hyperplasia/pyometra. Vet Rec 145: 455-457, 1999.

11. Coggan JA, Melville PA, Oliveira CM, Faustino M, Moreno AM and Benites NR: Microbiological and histopathological aspects of canine pyometra. Braz J Microbiol 39: 477-483, 2008.

12. Wadås B, Kühn I, Lagerstedt AS and Jonsson P: Biochemical phenotypes of Escherichia coli in dogs: Comparison of isolates isolated from bitches suffering from pyometra and urinary tract infection with isolates from faeces of healthy dogs. Vet Microbiol 52: 293-300, 1996.

13. Krekeler N, Marenda MS, Browning GF, Holden KM, Charles JA and Wright PJ: Uropathogenic virulence factor FimH facilitates binding of uteropathogenic Escherichia coli to canine endometrium. Comp Immunol Microbiol Infect Dis 35: 461-467, 2012.

14. Ghanbarpour R and Akhtardanesh B: Genotype and antibiotic resistance profile of Escherichia coli strains involved in canine pyometra. Comp Clin Pathol 21: 737-744, 2012

15. Chen YM, Wright PJ, Lee CS and Browning GF: Uropathogenic virulence factors in isolates of Escherichia coli from clinical cases of canine pyometra and feces of healthy bitches. Vet Microbiol 94: 57-69, 2003.

16. Ma Q, Liu N, Cong L, Lan Z, Wang X, Ma X, Li X and Ou G: Comparison between modified filmplate $\sim(T M)$ method and national standard method for the detection of coliform groups. J Pre Med Chin People's Liberation Army 33, 2015.

17. Siqueira AK, Ribeiro MG, Leite Dda S, Tiba MR, Moura Cd, Lopes MD, Prestes NC, Salerno T and Silva AV: Virulence factors in Escherichia coli strains isolated from urinary tract infection and pyometra cases and from feces of healthy dogs. Res Vet Sci 86: 206-210, 2009.

18. Livak KJ and Schmittgen TD: Analysis of relative gene expression data using real-time quantitative PCR and the 2(-Delta Delta C(T)) Method. Methods 25: 402-408, 2001.

19. Feldman E and Nelson R: The Cystic Endometrial Hyperplasia/Pyometra Complex. In: Proceedings of the University of Sydney, Post Graduate Foundation In Veterinary Science. Post Graduate Foundation in Veterinary Science, University of Sydney, Sydney, pp351-366, 1997.

20. Fieni F, Martal J, Marnet PG, Siliart B and Guittot F: Clinical, biological and hormonal study of mid-pregnancy termination in cats with aglepristone. Theriogenology 66: 1721-1728, 2006.

21. Nomura K, Kamomae H, Koreeda T and Tsuruno S: Clinical signs, intrauterine bacteria and plasma progesterone level in bitches with pyometra. J Japan Vet Med Assoc 37: 83-89, 1984.

22. Concannon PW, Hansel W and Visek WJ: The ovarian cycle of the bitch: Plasma estrogen, LH and progesterone. Biol Reprod 13: 112-121, 1975.

23. kumari Baithalu R, Maharana BR, Mishra C, Sarangi L and Samal L: Canine pyometra. Vet World 3: 340-342, 2010. 